\title{
Adhesion Strength of Cellulosic Varnish Coated Wood Species as Function of Their Surface Roughness
}

\author{
Turgay Ozdemir, ${ }^{1}$ Salim Hiziroglu, ${ }^{2}$ and Mutlu Kocapınar ${ }^{1}$ \\ ${ }^{1}$ Department of Forest Products Engineering, Karadeniz Technical University, Trabzon, Turkey \\ ${ }^{2}$ Resource Ecology and Management, Oklahoma State University, Stillwater, OK 74078, USA \\ Correspondence should be addressed to Salim Hiziroglu; salim.hiziroglu@okstate.edu
}

Received 28 November 2014; Revised 28 January 2015; Accepted 9 February 2015

Academic Editor: Jun Liu

Copyright (c) 2015 Turgay Ozdemir et al. This is an open access article distributed under the Creative Commons Attribution License, which permits unrestricted use, distribution, and reproduction in any medium, provided the original work is properly cited.

\begin{abstract}
The objective of this study was to evaluate adhesion strength of four wood species, namely, beech (Fagus orientalis Lipsky), alder (Alnus glutinosa subsp. barbata Yalt.), spruce (Picea orientalis L. Link), and fir (Abies nordmanniana subsp.) coated with cellulosic varnish. Samples were prepared in tangential and radial grain orientations from the above species. Surface quality of the specimens was also measured employing stylus type equipment after samples of all four types of species were sanded with 80- and 180-grit sandpaper prior to coating process. Surface roughness of the specimens sanded with 80-grit sandpaper resulted in significantly higher mean peak-to-valley height $\left(R_{z}\right)$ values based on the measurement employing stylus type profilometer. The highest adhesion strength values of $2.39 \mathrm{~N} / \mathrm{mm}^{2}$ and $2.03 \mathrm{~N} / \mathrm{mm}^{2}$ were found for beech and alder samples, respectively. It appears that overall higher roughness characteristics of the specimens exhibited enhanced adherence between substrate and varnish resulting in higher adhesion strength values.
\end{abstract}

\section{Introduction}

Hygroscopic characteristics of wood products play an important role in their effective utilization. Although there are many methods to enhance stability and appearance of wood, finishing is still considered as the most popular one among the others. Coating the surface of wood with different types of finishes will not only improve its appearance but also extend its service life. Final quality of coating applied to the surface of wood is influenced by various parameters; namely, species, roughness, porosity, density, and interaction between coating and the substrate [1-3]. Wood, being a nonhomogeneous material, sapwood, and heartwood ratio will also affect overall quality of coating [3].

Adhesive strength of coating on the surface can be evaluated with several techniques such as tape peel, observing the crosscut, and pull-off test. The last one was effectively employed to evaluate adhesion strength of wood and wood products coated with different finishes in previous studies [4-6]. The adhesion strength of stained, bleached, and preservative-treated wood specimens from oak and beech was evaluated in a past study [7]. It was found that bleaching had an adverse influence on adhesion strength of coated samples while stained samples had an average adhesion strength of $1.58 \mathrm{~N} / \mathrm{mm}^{2}$ [7]. Oak samples were coated with polyurethane base varnish and the effect of moisture content was also investigated in another study [8]. Various works have also been carried out to determine surface roughness of wood samples, in relation to their adhesion strength, coated with different finishes [8-11].

Another past study evaluated surface characteristics of radial and tangential grain orientations of three different hardwood species and concluded that rougher surfaces required higher amount of finishing material and overall quality of finishing was influenced by the surface roughness of the substrate [10]. Adhesion strength of oak and beech specimens coated with polyurethane varnishes was studied by Jaic and Zivanovic [4]. It was found that $10.3 \%$ moisture content of the samples resulted in the highest adhesion values for both species [8]. Burdurlu et al. compared adhesion strength of pine wood finished with polyurethane and sheen stain and found that polyurethane coating resulted in better 


\begin{tabular}{cc}
\hline \multicolumn{2}{c}{$R$-profile } \\
\hline$\lambda_{c}$ & $2.5 \mathrm{~mm}$ \\
$N$ & 3 \\
$R_{a}$ & $4.83 \mu \mathrm{m}$ \\
$R_{y}$ & $39.20 \mu \mathrm{m}$ \\
$R_{z}$ & $33.87 \mu \mathrm{m}$ \\
\hline
\end{tabular}

\begin{tabular}{cc}
\hline \multicolumn{2}{c}{$R$-profile } \\
\hline$\lambda_{c}$ & $2.5 \mathrm{~mm}$ \\
$N$ & 3 \\
$R_{a}$ & $5.40 \mu \mathrm{m}$ \\
$R_{y}$ & $45.20 \mu \mathrm{m}$ \\
$R_{z}$ & $41.57 \mu \mathrm{m}$ \\
\hline
\end{tabular}

\begin{tabular}{cc}
\hline \multicolumn{2}{c}{$R$-profile } \\
\hline$\lambda_{c}$ & $2.5 \mathrm{~mm}$ \\
$N$ & 3 \\
$R_{a}$ & $3.95 \mu \mathrm{m}$ \\
$R_{y}$ & $36.50 \mu \mathrm{m}$ \\
$R_{z}$ & $27.15 \mu \mathrm{m}$ \\
\hline
\end{tabular}

\begin{tabular}{cc}
\hline \multicolumn{2}{c}{$R$-profile } \\
\hline$\lambda_{c}$ & $2.5 \mathrm{~mm}$ \\
$N$ & 3 \\
$R_{a}$ & $5.31 \mu \mathrm{m}$ \\
$R_{y}$ & $40.22 \mu \mathrm{m}$ \\
$R_{z}$ & $35.22 \mu \mathrm{m}$
\end{tabular}
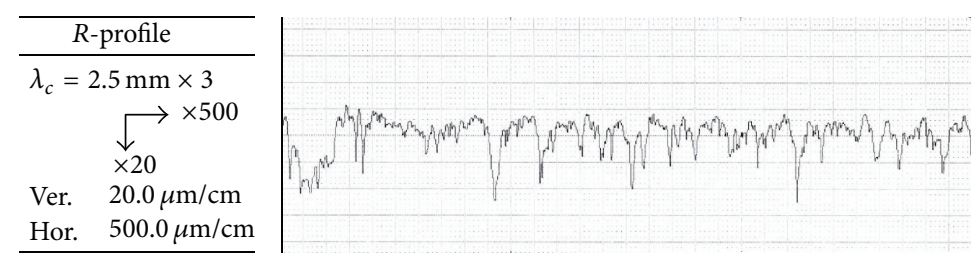

(a)
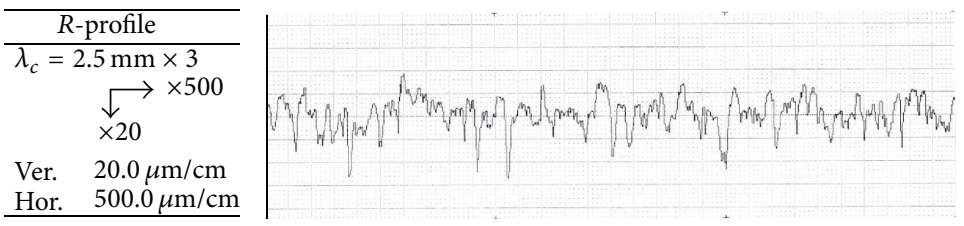

(b)
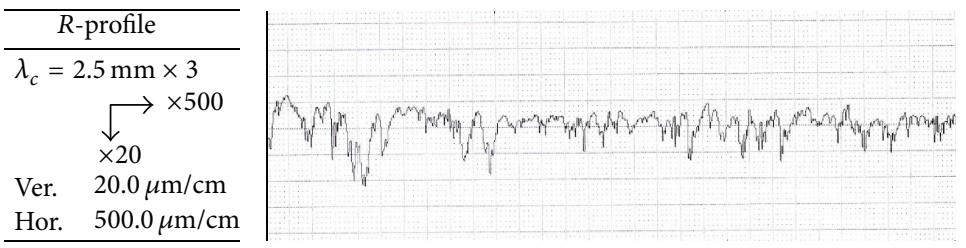

(c)
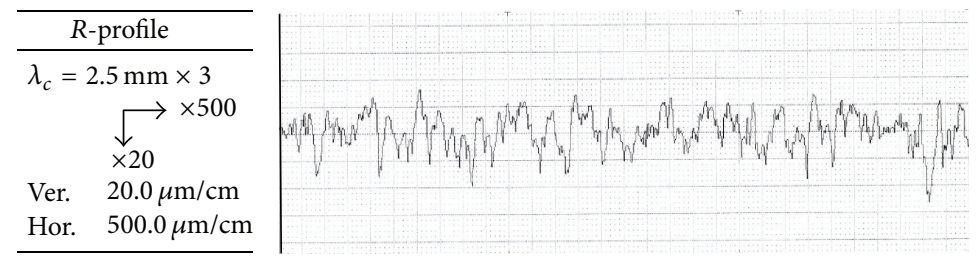

(d)

FIgURE 1: Typical roughness profiles of two species (from top to bottom; alder, 180-grit; alder, 80-grit; fir, 180-grit; fir, 80-grit).

strength values [8]. In general it is expected that rougher surface of the substrate results in better bonding ability of peak and valley points of the surface. As it is well known, surface roughness of the substrate will also influence the amount of finishing used controlling overall production cost. Therefore, subjective numerical information on the surface quality of the wood would provide valuable information so that not only amount of finishing chemical can be controlled but also final product can be manufactured with a better quality.

Almost all physical and mechanical properties of four species considered in this work were studied [12]. However, there is little or no information on how cellulose based varnishes adhere to their surfaces as function of their surface roughness. Therefore, it was the objective of this experimental study to evaluate adhesion strength of the samples from four species along with their surface roughness so that these species can be used with a better efficiency and higher quality to manufacture value-added products.

\section{Experimental}

2.1. Materials and Methods. A total of 240 defect-free, 60 for each species were prepared from beech (Fagus orientalis
Lipsky), alder (Alnus glutinosa subsp. barbata Yalt.), spruce (Picea orientalis L. Link), and fir (Abies nordmanniana subsp.) for the experiments. Samples with dimensions of $400 \mathrm{~mm}$ by $100 \mathrm{~mm}$ by $200 \mathrm{~mm}$ were conditioned in a climate room having a relative humidity of $65 \%$ and a temperature of $20^{\circ} \mathrm{C}$ until they reach equilibrium moisture content of $12 \%$. Conditioned specimens were sanded with 80 -grit and 180 -grit sandpaper using a commercial drum type sander. Although there are various roughness measurement techniques including pneumatic, laser, and light scattering methods to evaluate surface quality of wood and wood products, stylus type of profilometer is the most commonly used one due to its practicality and providing numerical result with an accuracy. Therefore, Mitutoyo SJ-301 profilometer was employed to measure roughness of the samples. Figure 1 illustrates typical roughness profiles of the samples sanded with 80 - and 180grit sandpapers.

Equipment has stylus with $0.5 \mu$ radius and $90^{\circ}$ contact angle running at a speed of $0.5 \mathrm{~mm} / \mathrm{s}$. A total of 25 random measurements with a span of $15 \mathrm{~mm}$ were taken from the surface of each radial and tangential sample across the grain orientation. Mean peak-to-valley height $\left(R_{z}\right)$ which is well accepted roughness parameter was used as an indicator of the surface quality of the samples $[13,14]$. 
TABLE 1: Roughness and adhesion strength test results.

\begin{tabular}{lcccccccc}
\hline & \multicolumn{3}{c}{ Roughness value $\left(R_{z}\right)(\mu \mathrm{m})$} & \multicolumn{4}{c}{ Adhesion strength $\left(\mathrm{N} / \mathrm{mm}^{2}\right)$} \\
Species grit size & \multicolumn{2}{c}{ Tangential } & \multicolumn{2}{c}{ Radial } & \multicolumn{3}{c}{ Tangential } & \multicolumn{2}{c}{ Radial } \\
& 80 & 180 & 80 & 180 & 80 & 180 & 80 & 180 \\
\hline Beech & 35.10 & 29.85 & 34.39 & 32.85 & 2.42 & 2.36 & 2.18 & 2.13 \\
$\left(0.680 \mathrm{~g} / \mathrm{cm}^{3}\right)$ & $(3.82)^{*}$ & $(3.38)$ & $(4.64)$ & $(3.44)$ & $(0.19)$ & $(0.25)$ & $(0.23)$ & $(0.25)$ \\
Alder & 37.66 & 33.69 & 35.81 & 30.81 & 2.15 & 1.92 & 2.01 & 1.96 \\
$\left(0.520 \mathrm{~g} / \mathrm{cm}^{3}\right)$ & $(5.62)$ & $(3.40)$ & $(3.66)$ & $(4.83)$ & $(0.28)$ & $(0.12)$ & $(0.18)$ & $(0.29)$ \\
Spruce & 36.98 & 32.10 & 35.13 & 26.05 & 2.06 & 1.92 & 2.00 & 1.93 \\
$\left(0.420 \mathrm{~g} / \mathrm{cm}^{3}\right)$ & $(3.98)$ & $(8.61)$ & $(4.33)$ & $(3.03)$ & $(0.40)$ & $(0.25)$ & $(0.22)$ & $(0.16)$ \\
Fir & 37.00 & 27.53 & 36.68 & 24.03 & 2.06 & 1.91 & 1.89 & 1.86 \\
$\left(0.680 \mathrm{~g} / \mathrm{cm}^{3}\right)$ & $(4.39)$ & $(6.68)$ & $(4.42)$ & $(3.69)$ & $(0.32)$ & $(0.29)$ & $(0.15)$ & $(0.18)$ \\
\hline
\end{tabular}

*Values in parentheses are standard deviations.

The specimens were coated with cellulosic varnish with $35 \%$ solid content having viscosity of $300 \mathrm{sec}$. DIN cup $/ 4 \mathrm{~mm}$ and density of $0.95 \mathrm{~g} / \mathrm{cm}^{3}$ using a pressurized spray gun at a spread rate of $120 \mathrm{~g} / \mathrm{m}^{2}$. Coating was applied to the samples in two sequential steps, namely initial coating and the final coating. After the initial coating, samples were dried in room temperature and sanded with sandpaper having 220grit sandpaper. In the next step, the final coating was applied and dried specimens were also sanded using aluminum oxide sandpaper with 400-grit sandpaper. Erichsen Adhesion-525 MC pull-off type tester was employed for adhesion strength evaluation of the specimens. Twenty random measurements were taken from the surface of the samples by gluing steel head with $20 \mathrm{~mm}$ diameter using epoxy resin on the samples. The equipment was run at a constant speed of $100 \mathrm{~mm} / \mathrm{min}$ and applied the force to the surface layer by pulling the coating from the surface. Adhesion strength value of the finishing is recorded in $\mathrm{N} / \mathrm{mm}^{2}$ on the display of the pulloff testing unit. Figure 2 shows pull-off test setup used for the experiments. From each sample, $20 \mathrm{~mm}$ by $200 \mathrm{~mm}$ by $30 \mathrm{~mm}$ specimens were cut to measure their density. These small samples were weighed and their dimensions were measured at accuracy of $0.1 \mathrm{~g}$ and $0.01 \mathrm{~mm}$, respectively. Variance analysis (ANOVA) and Duncan tests were used to analyze the test results.

\section{Results and Discussion}

Table 1 and Figure 3 show test results of the samples. The highest $R_{z}$ value of $37.66 \mu \mathrm{m}$ was found for alder samples sanded with 80-grit sandpaper in tangential direction followed by fir specimens sanded with the same grit size having the corresponding value of $37.00 \mu \mathrm{m}$. Once these samples were sanded with 180-grit sandpaper their average $R_{z}$ values reduced ranging from $10.5 \%$ to $25.5 \%$.

Both spruce and fir also resulted in similar $R_{z}$ values to those of the other two species considered in this work. In a previous work, $R_{z}$ value of beech control specimens was found to be $39.94 \mu \mathrm{m}$ which is similar to the results in this work [10]. Spruce and fir species had smoother surface quality than those of beech and alder when they were sanded with higher grit size sandpaper. This could be related to

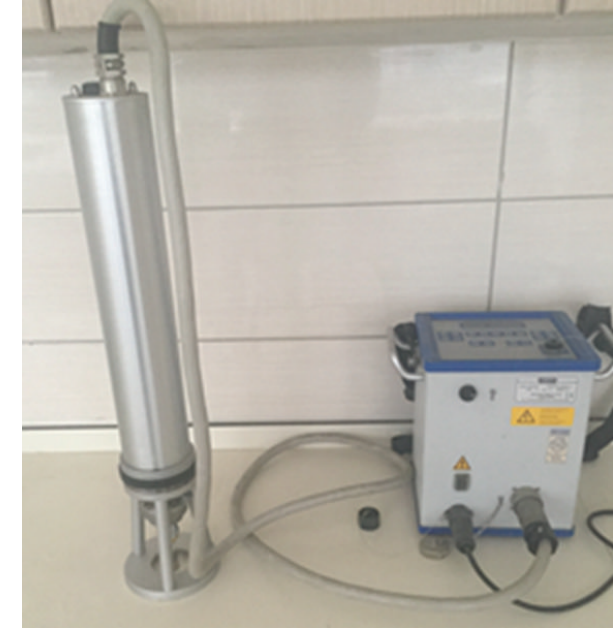

FIGURE 2: Pull-off test setup used for the experiments.

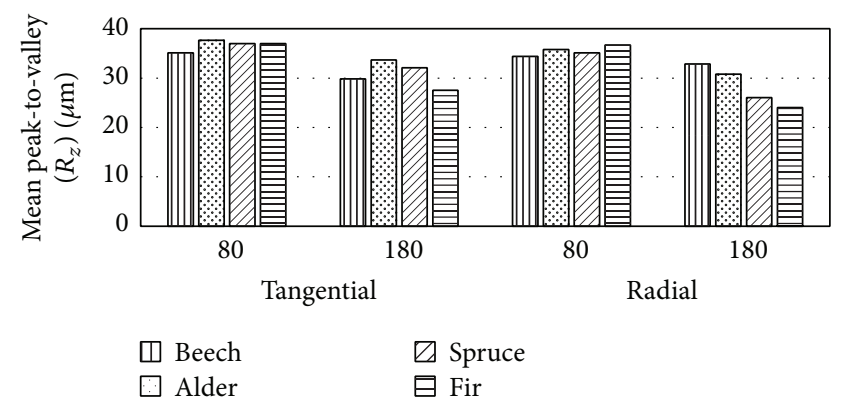

FIGURE 3: Mean peak-to-valley values of the samples.

low density of both softwood species. Based on the ANOVA analysis, no significant difference was found between $R_{z}$ values determined from the tangential and radial surfaces for all four types of species as displayed in Table 2 .

The highest adhesion strength value of $2.42 \mathrm{~N} / \mathrm{mm}^{2}$ was determined for beech samples sanded with 80-grit size sandpaper in tangential direction. Alder had $2.15 \mathrm{~N} / \mathrm{mm}^{2}$ for corresponding value as can be seen in Figure 4. Both spruce and fir resulted in $2.06 \mathrm{~N} / \mathrm{mm}^{2}$ and $2.05 \mathrm{~N} / \mathrm{mm}^{2}$ adhesion 
TABLE 2: Statistical analysis of the roughness and adhesion strength test results.

\begin{tabular}{|c|c|c|c|c|c|}
\hline Source & Sum of squares & df & Mean square & $F$ value & $\begin{array}{c}\text { Significance } \\
\text { level }\end{array}$ \\
\hline \multicolumn{6}{|c|}{ Surface roughness } \\
\hline Effect of species $(A)$ & 519.576 & 3 & 173.192 & 7.814 & $* * *$ \\
\hline Effect of grain orientation $(B)$ & 313.361 & 1 & 313.361 & 14.137 & $* * *$ \\
\hline Effect of sanding $(C)$ & 4197.226 & 1 & 4197.226 & 189.359 & $* * *$ \\
\hline$A \times B$ & 340.698 & 3 & 113.566 & 5.124 & $* *$ \\
\hline$A \times C$ & 867.98 & 3 & 289.323 & 13.053 & $* * *$ \\
\hline$B \times C$ & 35.058 & 1 & 35.058 & 1.582 & NS \\
\hline$A \times B \times C$ & 231.369 & 3 & 77.123 & 3.479 & $*$ \\
\hline Error & 8511.533 & 384 & 22.165 & & \\
\hline Total & 446911.543 & 400 & & & \\
\hline Source & Sum of squares & $\mathrm{df}$ & Mean square & $F$ value & $\begin{array}{c}\text { Significance } \\
\text { level }\end{array}$ \\
\hline \multicolumn{6}{|c|}{ Adhesion strength } \\
\hline Effect of species $(A)$ & 5.650 & 3 & 1.883 & 30.206 & $* * *$ \\
\hline Effect of grain orientation $(B)$ & 0.896 & 1 & 0.896 & 14.367 & $* * *$ \\
\hline Effect of sanding $(C)$ & 0.746 & 1 & 0.746 & 11.965 & $* * *$ \\
\hline$A \times B$ & 0.520 & 3 & 0.173 & 2.783 & * \\
\hline$A \times C$ & 0.064 & 3 & 0.021 & 0.343 & NS \\
\hline$B \times C$ & 0.183 & 1 & 0.183 & 2.933 & NS \\
\hline$A \times B \times C$ & 0.081 & 3 & 0.027 & 0.431 & NS \\
\hline Error & 18.953 & 304 & & & \\
\hline Total & 1374.395 & 320 & & & \\
\hline
\end{tabular}

NS: nonsignificant; ${ }^{*}$ significant at the $\alpha=0.05$ level; ${ }^{* *}$ significant at the 0.01 level; ${ }^{* * *}$ significant at the $\alpha=0.001$ level.

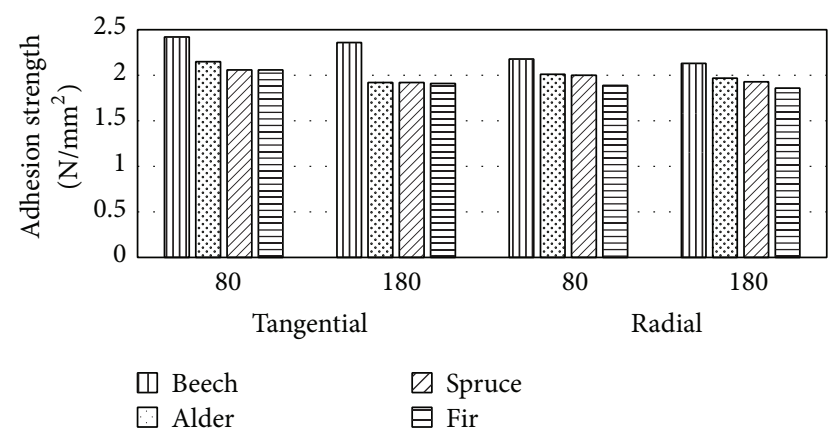

Figure 4: Adhesion strength values of the samples.

strength values when they were sanded with 80 -grit size sandpaper. It is a well-known fact that anatomical structure is one of the major parameters influencing overall interaction between coating and substrate. Both alder and beech being semiporous structure would result in better absorption of the varnish causing higher magnitude of interaction between the two elements.

No significant difference was found between adhesion strength values of two softwood species based on ANOVA and Duncan test as displayed in Tables 2 and 3. Even though they were sanded with finer sand paper, their strength values did not go down in contrast to alder and beech. It seems that varnish had deeper penetration due to more porous structure than that of spruce and fir samples as mentioned above. In another study, ash which is also porous species had enhanced adhesion strength characteristics as it is sanded with coarse sand paper.

\section{Conclusions}

In this study, adhesion strength of cellulosic varnish coated wood samples was determined as function of their surface roughness. Based on the findings in this work, it seems that adhesion strength of the samples improved when they were sanded with higher-grit sandpaper with increasing their surface roughness characteristics evaluated using a stylus type of equipment. Tangential and radial grain orientations of the specimens did not make any significant differences in their roughness and adhesion strength values. Anatomical structure of the species would be considered one of the factors influencing roughness as well as development of bonding between coating and the samples. Softwood species having lower density levels resulted in smoother surface when they were sanded with rougher sandpaper. Preliminary data determined in this experimental work could possibly be used as quality control tool to improve overall finishing application of the members manufactured from these four species. In further studies, it would be desirable to investigate wettability of the varnished samples to have a better understanding of 
TABLE 3: Duncan test results of the samples.

\begin{tabular}{|c|c|c|c|}
\hline $\begin{array}{l}\text { Strength } \\
\text { properties }\end{array}$ & Factors & $\begin{array}{c}\text { LS } \\
\text { mean }\end{array}$ & $\begin{array}{c}\text { Homogenous } \\
\text { groups }\end{array}$ \\
\hline \multirow{11}{*}{$\begin{array}{l}\text { Surface } \\
\text { roughness }\end{array}$} & Wood species & & \\
\hline & Beech & 33.053 & $\mathrm{~b}$ \\
\hline & Alder & 34.498 & a \\
\hline & Spruce & 32.571 & $\mathrm{bc}$ \\
\hline & Fir & 31.313 & c \\
\hline & Grain orientation & & \\
\hline & Tangential & 33.744 & a \\
\hline & Radial & 31.974 & $\mathrm{~b}$ \\
\hline & Grit size & & \\
\hline & 80 & 36.099 & a \\
\hline & 180 & 29.620 & $\mathrm{~b}$ \\
\hline \multirow{11}{*}{$\begin{array}{l}\text { Adhesion } \\
\text { strength }\end{array}$} & Species & & \\
\hline & Beech & 2.277 & a \\
\hline & Alder & 2.012 & $\mathrm{~b}$ \\
\hline & Spruce & 1.981 & $\mathrm{~b}$ \\
\hline & Fir & 1.936 & $\mathrm{~b}$ \\
\hline & Grain orientation & & \\
\hline & Tangential & 2.105 & a \\
\hline & Radial & 1.999 & $\mathrm{~b}$ \\
\hline & Grit size & & \\
\hline & 80 & 2.100 & $\mathrm{a}$ \\
\hline & 180 & 2.004 & $\mathrm{~b}$ \\
\hline
\end{tabular}

${ }^{*}$ Different letters indicate statistically significant difference between the groups.

their behavior along with exposure to different conditions having fluctuating relative humidity levels.

\section{Conflict of Interests}

The authors declare no conflict of interests.

\section{Acknowledgment}

This study was carried out with financial assistance of Research Program, Karadeniz Technical University, Trabzon, Turkey.

\section{References}

[1] A. V. Pocius, Adhesion and Adhesives Technology: An Introduction, vol. 21, Hanser and Gardnes Publications, 2nd edition, 2002.

[2] J. Schultz and M. Nardin, "Theories and mechanism of adhesion," in Handbook of Adhesive Technology, pp. 19-35, Marcel Dekker, New York, NY, USA, 1994.

[3] E. Cheng and X. Sun, "Effects of wood-surface roughness, adhesive viscosity and processing pressure on adhesion strength of protein adhesive," Journal of Adhesion Science and Technology, vol. 20, no. 9, pp. 997-1017, 2006.
[4] M. Jaic and R. Zivanovic, "The influence of the ratio of the polyurethane coating components on the quality of finished wood surface," Holz als Roh-und Werkstoff, vol. 55, no. 5, pp. 319-322, 1997.

[5] E. Zavarin, "Activation of wood surface and non-conventional bonding," in The Chemistry of Solid Wood, R. Rowell, Ed., pp. 349-400, ACS, Washington, DC, USA, 1984.

[6] T. Ozdemir, S. Hiziroglu, and A. Malkocoglu, "Influence of relative humidity on surface quality and adhesion strength of coated medium density fiberboard (MDF) panels," Materials and Design, vol. 30, no. 7, pp. 2543-2546, 2009.

[7] M. Jaić, R. Živanovic, T. Stevanović-Janežić, and A. Dekanski, "Comparison of surface properties of beech- and oakwood as determined by ESCA method," Holz als Roh- und Werkstoff, vol. 54, no. 1, pp. 37-41, 1996.

[8] E. Burdurlu, Y. Kiliç, G. Cankiz Elibol, and M. Kiliç, “The shear strength of calabrian pine (Pinus brutia ten.) bonded with polyurethane and polyvinyl acetate adhesives," Journal of Applied Polymer Science, vol. 99, no. 6, pp. 3050-3061, 2006.

[9] T. Ozdemir and S. Hiziroglu, "Influence of surface roughness and species on bond strength between the wood and the finish," Forest Products Journal, vol. 59, no. 6, pp. 90-94, 2009.

[10] T. Ozdemir and S. Hiziroglu, "Evaluation of surface quality and adhesion strength of treated solid wood," Journal of Materials Processing Technology, vol. 186, no. 1-3, pp. 311-314, 2007.

[11] Z. W. Wick, F. N. Jones, and S. P. Papas, Organic Coatings: Science and Technology, Wiley Interscience, New York, NY, USA, 2nd edition, 1998.

[12] USDA Forest Service and Forest Products Laboratory, Wood Handbook: Wood as an Engineering Material, GTR -113, USDA Forest Service, Forest Products Laboratory, Madison, Wis, USA, 1999.

[13] S. Hiziroglu, "Surface roughness analysis of wood composites: a stylus method," Forest Products Journal, vol. 46, no. 7-8, pp. 67-72, 1996.

[14] L. Mummery, "Surface texture analysis," in The Handbook, p. 106, Hommelwelke, Mühlhausen, Germany, 1991. 

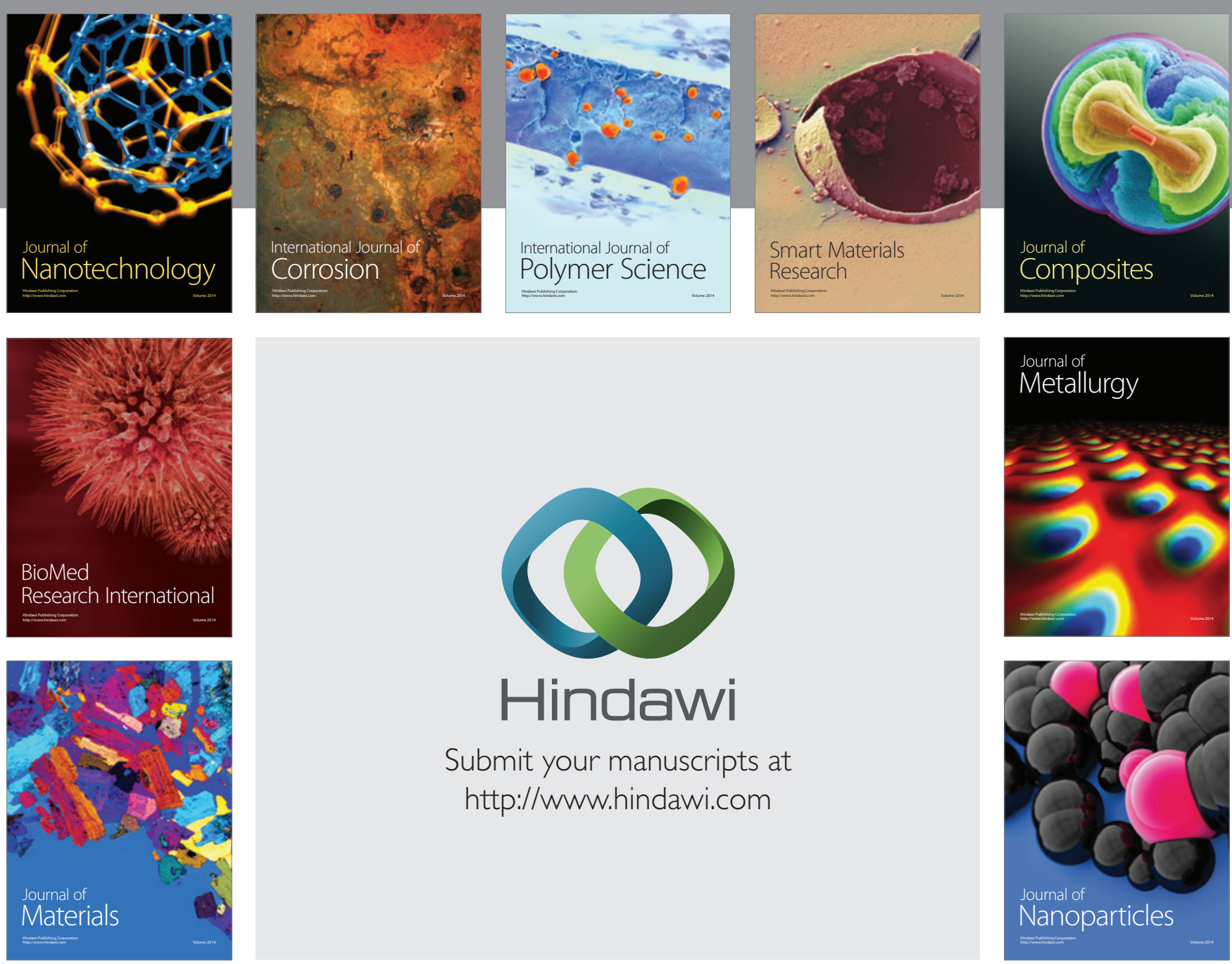

Submit your manuscripts at http://www.hindawi.com
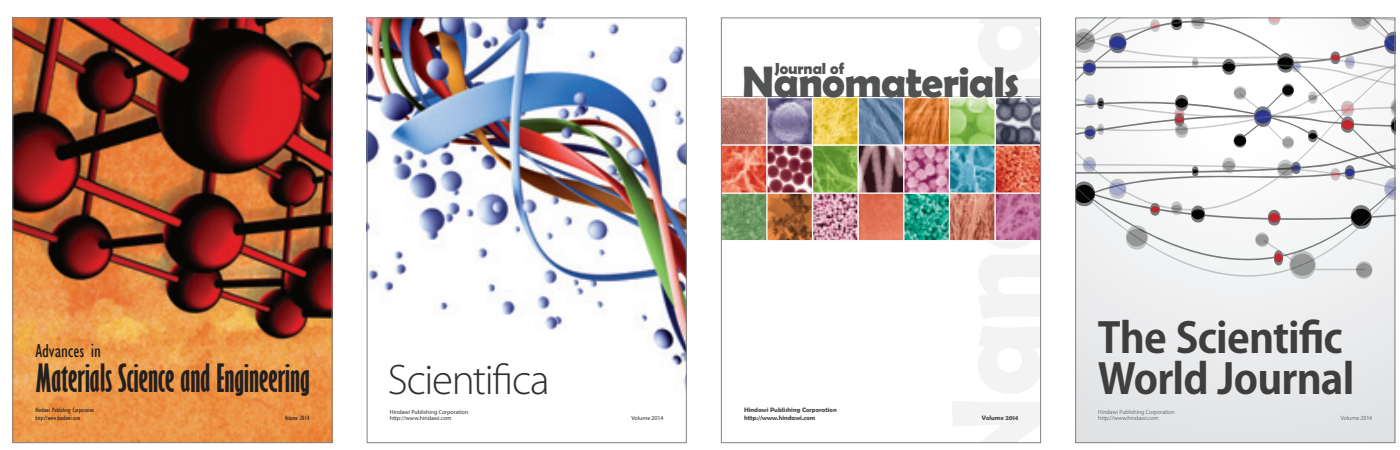

\section{The Scientific World Journal}
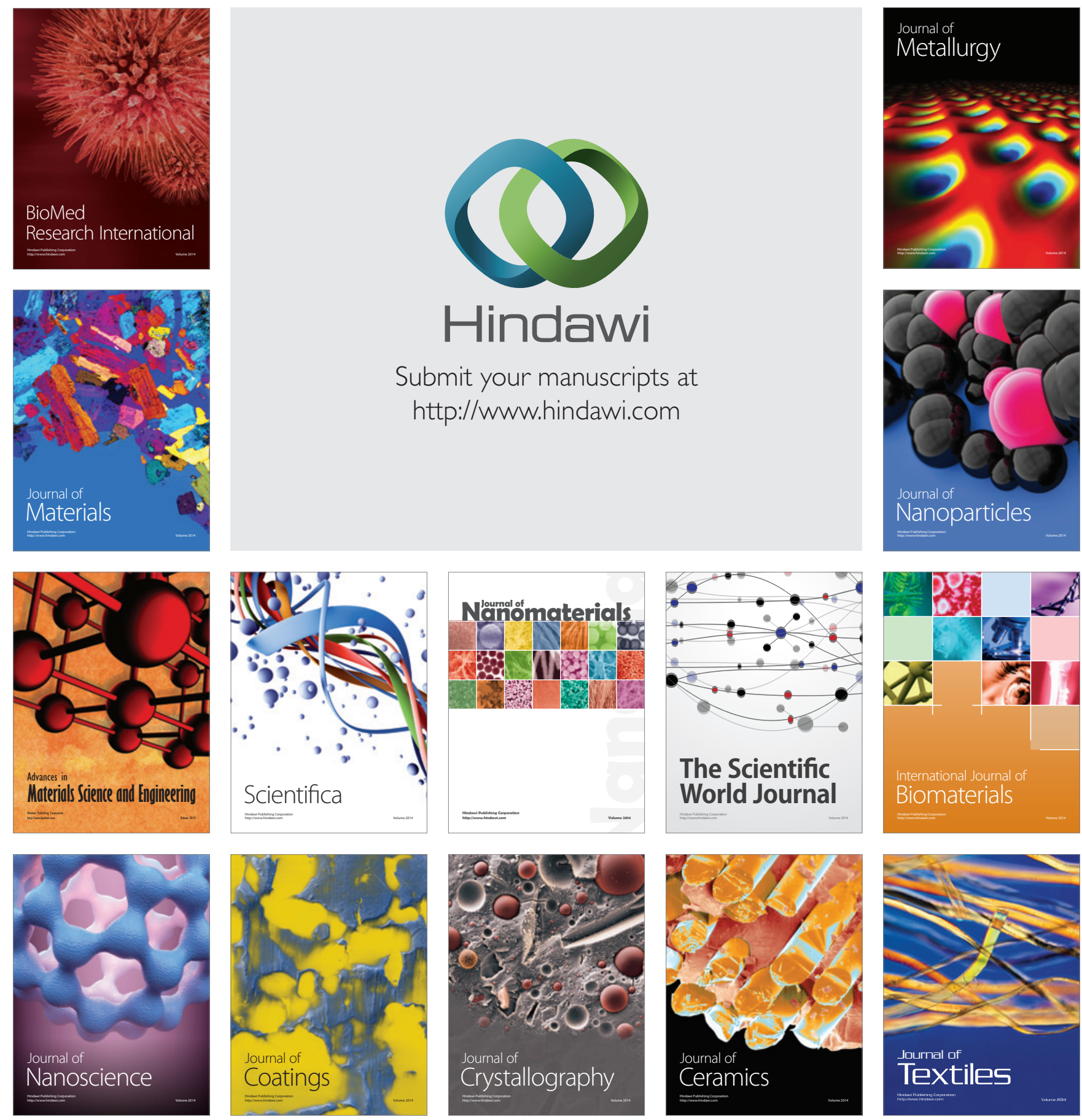